\title{
Microalbuminuria is strongly associated with NIDDM and hypertension, but not with the insulin resistance syndrome: the Hoorn Study
}

\author{
A.Jager ${ }^{1}$, P.J. Kostense ${ }^{1,2}$, G. Nijpels ${ }^{1}$, R.J.Heine ${ }^{1,3}$, L.M. Bouter ${ }^{1,2}$, C.D. A.Stehouwer ${ }^{1,3}$ \\ ${ }^{1}$ Institute for Research in ExtramuraI Medicine, Vrije Universiteit, Amsterdam, The Netherlands \\ ${ }^{2}$ Department of Epidemiology and Biostatistics, Vrije Universiteit, Amsterdam, The Netherlands \\ ${ }^{3}$ Department of Internal Medicine, Academic Hospital Vrije Universiteit, Amsterdam, The Netherlands
}

\begin{abstract}
Summary Microalbuminuria is a strong predictor of cardiovascular disease. The aim of this study was to investigate whether microalbuminuria is part of a cluster of risk factors, the insulin resistance syndrome (IRS), or whether it is only associated with, and presumably a complication of, hypertension and non-insulin-dependent diabetes mellitus (NIDDM). An age-, sex- and glucose tolerance-stratified random sample from a 50-75 year old general population $(n=622)$ was investigated. The urinary albumin-tocreatinine ratio was measured in an early morning spot urine sample. Microalbuminuria was defined as an albumin-to-creatinine ratio greater than $2.0 \mathrm{mg} /$ mmol. We considered, as IRS-related variables, fasting hyperinsulinaemia, insulin resistance (IR; calculated from the formula of the homeostasis model assessment), dyslipidaemia, glucose intolerance, hypertension and waist-to-hip ratio (WHR). Dyslipidaemia was defined as levels of HDL-cholesterol in the lowest and / or levels of triglyceride in the highest tertile. Fasting insulin levels, IR and WHR were divided into tertiles; the highest tertiles were compared to the lowest tertiles. Age-, sex- and glucose tolerance-ad-
\end{abstract}

justed analyses showed microalbuminuria to be significantly associated with hypertension, NIDDM and WHR. In multiple logistic regression analyses, microalbuminuria showed independent associations with hypertension, NIDDM and WHR, with odds ratios (ORs $[95 \%$ confidence interval]) of 3.33 (1.86-5.96), 2.26 (1.14-4.48) and 2.49 (1.09-5.70), respectively. No associations were found with impaired glucose tolerance, hyperinsulinaemia, IR or dyslipidaemia. Multiple logistic regression analyses in diabetic and non-diabetic subjects separately showed that microalbuminuria was independently associated only with hypertension (ORs 4.31 and 2.69). In this Caucasian population, microalbuminuria was associated with hypertension, NIDDM and WHR and not with other variables of the IRS. It is therefore likely that microalbuminuria is a complication of hypertension and NIDDM, and not an integral part of the IRS. [Diabetologia (1998) 41: 694-700]

Keywords Microalbuminuria, insulin resistance syndrome, non-diabetic subjects, non-insulin-dependent diabetes mellitus, hypertension, population.
Received: 7 August 1997 and in revised form: 5 January 1998

Corresponding author: Dr. A. Jager, Institute for Research in Extramural Medicine, Faculty of Medicine, Vrije Universiteit, Van der Boechorstraat 7, NL-1081 BT Amsterdam, The Netherlands

Abbreviations: MA, Microalbuminuria; NIDDM, non-insulindependent diabetes mellitus; IGT, impaired glucose tolerance; IRS, insulin resistance syndrome; IR, insulin resistance; WHO, World Health Organisation; NGT, normal glucose tolerance; WHR, waist-to-hip ratio; ACR, albumin-to-creatinine ratio; OR, odds ratio; $95 \% \mathrm{CI}, 95 \%$ confidence interval; HOMA, homeostasis model assessment.
Microalbuminuria (MA) is associated with an increased risk of cardiovascular disease in non-insulindependent diabetes mellitus (NIDDM) [1-3], as well as in the apparently healthy middle-aged and elderly general population $[4,5]$. It has been proposed that MA belongs to a cluster of risk factors known as the insulin resistance syndrome (IRS), which implies that MA would be closely associated not only with hypertension [6-9] and NIDDM [10, 11], but also with impaired glucose tolerance (IGT) [10], obesity $[12,13]$, insulin resistance (IR) $[6,8,9,11,14]$, hyperinsulinaemia $[15,16]$ and dyslipidaemia $[6,16,17]$. 
These associations might then explain the association between MA and the increased risk of cardiovascular disease [6-11, 14-18]. Alternatively, MA may be a complication of hypertension and NIDDM, possibly reflecting endothelial dysfunction [19, 20], without having associations with other components of the IRS [21-23]. The latter hypothesis, if correct, implies that MA cannot be used as a marker for the IRS in the general population.

Previous experimental $[6,8,9,11,14,17,22]$ and epidemiological $[7,10,15,16,18,21,23]$ investigations of the link between MA and the IRS have yielded conflicting results. These studies have, however, been limited by not being population-based $[6-9,11$, $18,21,22]$, by including only part of the spectrum of glucose tolerance and the IRS [6-11, 14, 16, 17, 21, 23 ], and / or by not being ethnically homogeneous $[10,18,23]$. The latter is important, because the prevalence and the pathogenesis of MA may differ according to ethnicity. For example, non-Caucasian populations showed higher prevalences of MA than Caucasian populations, both among subjects with NIDDM [23-25] as well as among non-diabetic subjects $[16,18,25]$. In view of these considerations, we decided to study the association between MA and the IRS in a population-based, sex-, age- and glucose tolerance- stratified sample of an ethnically homogeneous, Caucasian population.

\section{Subjects and methods}

Subjects. The Hoorn Study is a cross-sectional survey of glucose intolerance and related complications in 2484 randomly selected Caucasian men and women aged 50-75 years as described in detail elsewhere [26]. Of this population, an age-, sex- and glucose tolerance-stratified sample of 680 subjects (279 with normal glucose tolerance [NGT], 219 with IGT and 182 with NIDDM [27]; based on one oral glucose tolerance test [OGTT]); $95.5 \%$ of those invited underwent a second OGTT (except those subjects with previously diagnosed NIDDM treated with oral blood glucose-lowering agents or insulin, $n=67$ [26]) and were asked to collect urine for measurement of the albumin-to-creatinine ratio (see below). The final definition of glucose tolerance was based on the mean of the two OGTTs (314 NGT, 192 IGT and 174 NIDDM subjects [27]). All participants gave their informed consent for these studies, which were approved by the local ethics committee.

Methods. Blood pressure, weight and height were measured and body mass index and waist-to-hip ratio (WHR) were calculated as previously described [26]. Information on smoking habits and protein intake was obtained by a self-administered questionnaire. We measured fasting and 2-h post-load venous plasma glucose levels, $\mathrm{HbA}_{1 \mathrm{c}}$, fasting plasma levels of insulin (with a specific assay) and proinsulin, and fasting serum levels of total cholesterol, HDL cholesterol and triglycerides, as described in detail elsewhere [26, 28]. Fasting proinsulin levels were not measured in previously diagnosed NIDDM $(n=67)$. The Friedewald formula was used to calculate the LDL cholesterol concentration, except when serum triglyceride was greater than $8.0 \mathrm{mmol} / \mathrm{l}(n=3)$ [29].
An early morning first voided spot urine sample was collected. The presence of leukocytes was tested by microscopy and scored as positive ( $>5$ leukocytes per high powerfield) or negative. Urinary albumin was measured by rate nephelometry (Array Protein System, Beckman, Galway, Ireland) with a threshold of $6.2 \mathrm{mg} / \mathrm{l}$ and intra- and inter-assay coefficients of variation of $5 \%$ and $8 \%$, respectively. Urinary creatinine was measured by a modified Jaffé method. The urinary albuminto-creatinine ratio (ACR) was calculated; ACR $\leq 2.0 \mathrm{mg}$ / mmol was defined as normoalbuminuria and ACR above $2.0 \mathrm{mg} / \mathrm{mmol}$ as microalbuminuria. (An overnight ACR > $2.0 \mathrm{mg} / \mathrm{mmol}$ predicts an albumin excretion rate $>30 \mu \mathrm{g} / \mathrm{min}$ with a high sensitivity and specificity [30].) The reproducibility of the ACR was calculated from a representative sample of 185 subjects who collected a second urine sample in similar fashion. The Kappa coefficient of the ACRs in these subjects was 0.59 , indicating moderate agreement [31]. The analyses were performed on 622 subjects of the initial 680; 24 urine samples were lost and 34 subjects used angiotensin converting enzyme inhibitors and were therefore excluded. For 174 subjects the ACR was based on the mean of two measurements. Six subjects had an ACR above $30 \mathrm{mg} / \mathrm{mmol}$, a level which approximates an albumin excretion of $300 \mathrm{mg} / 24 \mathrm{~h}$, i. e. the upper limit for microalbuminuria. Excluding these subjects from the analyses did not materially affect any of the results, which are therefore presented for the entire group.

Statistical analysis. All analyses were performed with the Statistical Package for the Social Sciences (SPSS). We postulated that if MA was part of the IRS, MA should be related not only to hypertension and NIDDM (of which MA may be a complication, as suggested by the alternative hypothesis described above), but also to dyslipidaemia, central obesity and hyperinsulinaemia or IR. Therefore, multiple logistic regression analyses were performed to investigate the association between the presence of MA and IRS-related variables. The Wald test was used to test significance. All odds ratios for MA were adjusted for age, sex and glucose tolerance. We used three different models, in which each separate variable was adjusted for the other IRS-related variables. In the first, we considered, as IRS-related variables, fasting hyperinsulinaemia, dyslipidaemia, glucose intolerance (i.e. IGT or NIDDM), hypertension and WHR [32, 33]. In the second, fasting hyperinsulinaemia was replaced by IR, according to the formula of the homeostasis model assessment: IR $=$ fasting insulin $\times$ fasting glucose / 22.4 [34]. (We chose fasting rather than post-glucose insulin levels as an estimate of IR, because fasting but not post-glucose insulin levels have been shown to correlate closely with insulin-mediated glucose uptake in both NGT and NIDDM [35].) In the third model, fasting hyperproinsulinaemia, another possible marker of IR [36], replaced fasting hyperinsulinaemia. Hypertension was defined as diastolic blood pressure over $95 \mathrm{mmHg}$ and / or systolic blood pressure over $160 \mathrm{mmHg}$ and / or the use of antihypertensive drugs. Dyslipidaemia was defined as levels of HDL-cholesterol in the lowest and / or triglycerides in the highest tertile. Fasting insulin levels, IR and WHR (separate per sex) were divided into tertiles; the highest tertiles were compared to the lowest.

Finally, to investigate as thoroughly as possible the putative association of MA with the IRS, we created two 'sum' Z-scores for each subject. For each IRS-related variable a Z-score ((value $(x)-$ mean $(x)) / \operatorname{sd}(x))$ was calculated. The first 'sum' Zscore was the sum of the Z-scores of the continuous variables reflecting NIDDM and hypertension, i.e. fasting glucose level and systolic and diastolic blood pressure. The second 'sum' Zscore was the sum of Z-scores of the other IRS-related variables, i. e. fasting levels of insulin, triglycerides and HDL-cho- 


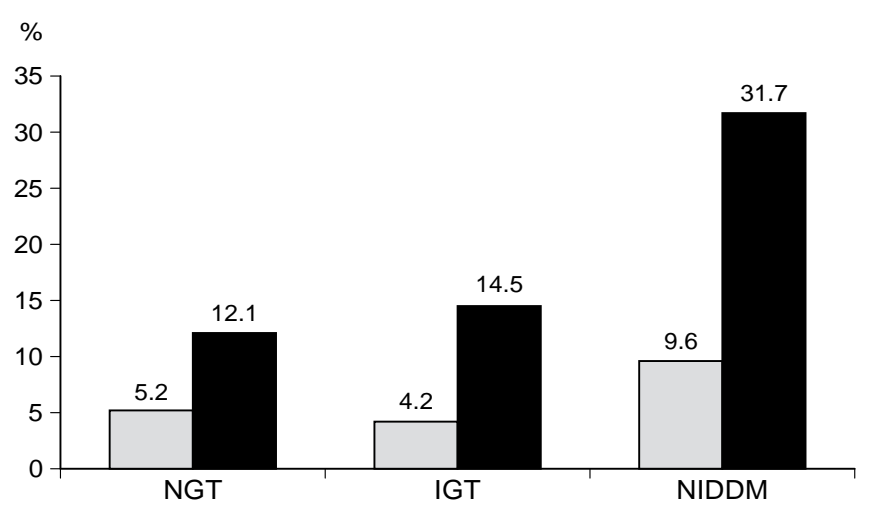

Fig. 1. Age-standardized prevalence of microalbuminuria in different glucose tolerance groups with or without hypertension, $\square=$ normotensive subjects, $\square=$ hypertensive subjects, NGT $=$ normal glucose tolerance, IGT $=$ impaired glucose tolerance, NIDDM = non-insulin-dependent diabetes mellitus. lesterol, and WHR, a higher Z-score indicating a more unfavourable spectrum. The idea of this analysis is that weak associations between MA and these other IRS-related variables might reveal themselves when considered in combination, even if each of these associations were too weak to be significant by themselves. Thus, to investigate whether higher 'sum' $\mathrm{Z}$-scores were associated with a higher risk of MA, we calculated the prevalence of MA in all combinations of tertiles of the two 'sum' Z-scores.

\section{Results}

The prevalence of MA in this sample was $10.9 \%$ (68/ 622) and was higher among diabetic than among non-diabetic subjects ( 21.3 vs $7.5 \%$ ) and among hypertensive than among non-hypertensive subjects (20.1 vs $5.8 \%$; Fig. 1 ). The prevalence of MA, in the general 50-75-year-old Caucasian population of Hoorn, age-standardized to the age distribution in the general population and calculated by direct standardisation, was $8.2 \%(22.6 \%$ and $6.9 \%$ among dia-

Table 1. Baseline characteristics of subjects with normo- and microalbuminuria

\begin{tabular}{|c|c|c|c|c|c|c|}
\hline & \multicolumn{2}{|c|}{$\begin{array}{l}\text { Normal glucose tolerance sub- } \\
\text { jects }\end{array}$} & \multicolumn{2}{|c|}{$\begin{array}{l}\text { Impaired glucose tolerance sub- } \\
\text { jects }\end{array}$} & \multicolumn{2}{|c|}{ Diabetic subjects } \\
\hline & $\begin{array}{l}\mathrm{ACR} \leq 2.0 \\
\mathrm{mg} / \mathrm{mmol}\end{array}$ & $\begin{array}{l}\mathrm{ACR}>2.0 \\
\mathrm{mg} / \mathrm{mmol}\end{array}$ & $\begin{array}{l}\mathrm{ACR} \leq 2.0 \\
\mathrm{mg} / \mathrm{mmol}\end{array}$ & $\begin{array}{l}\mathrm{ACR}>2.0 \\
\mathrm{mg} / \mathrm{mmol}\end{array}$ & $\begin{array}{l}\mathrm{ACR} \leq 2.0 \\
\mathrm{mg} / \mathrm{mmol}\end{array}$ & $\begin{array}{l}\mathrm{ACR}>2.0 \\
\mathrm{mg} / \mathrm{mmol}\end{array}$ \\
\hline $\bar{n}$ & 275 & 20 & 157 & 15 & 122 & 33 \\
\hline Sex (\% male) & 50 & 65 & 45 & 53 & 46 & 33 \\
\hline Age (years) & $63 \pm 7$ & $68 \pm 6$ & $65 \pm 7$ & $65 \pm 7$ & $66 \pm 7$ & $67 \pm 6$ \\
\hline Fasting glucose $(\mathrm{mmol} / \mathrm{l})$ & $5.4(5.1-5.7)^{\mathrm{a}}$ & $5.5(5.1-5.8)^{\mathrm{a}}$ & $5.9(5.5-6.6)^{\mathrm{a}}$ & $6.0(5.9-6.4)^{\mathrm{a}}$ & $7.5(6.4-8.5)^{\mathrm{a}}$ & $7.0(6.1-8.4)^{\mathrm{a}}$ \\
\hline $\mathrm{HbA}_{1 \mathrm{c}}$ (\% of haemoglobin) & $5.4 \pm 0.5$ & $5.2 \pm 0.5$ & $5.6 \pm 0.5$ & $5.6 \pm 0.4$ & $7.0 \pm 1.9$ & $8.0 \pm 1.7$ \\
\hline Fasting insulin (pmol/1) & $79(60-97)^{\mathrm{a}}$ & $80(66-110)^{\mathrm{a}}$ & $93(72-126)^{\mathrm{a}}$ & $79(65-151)^{\mathrm{a}}$ & $116(83-162)^{\mathrm{a}}$ & $131(82-168)^{\mathrm{a}}$ \\
\hline Hyperinsulinaemia $(\%)^{\mathrm{b}}$ & 18 & 30 & 41 & 40 & 55 & 58 \\
\hline $\begin{array}{l}\text { Insulin resistance } \\
\left(\mathrm{pmol} \cdot \mathrm{mmol} \cdot \mathrm{l}^{-2}\right)^{\mathrm{c}}\end{array}$ & $19(14-23)^{\mathrm{a}}$ & $20(16-26)^{\mathrm{a}}$ & $25(18-34)^{\mathrm{a}}$ & $20(18-46)^{\mathrm{a}}$ & $38(26-57)^{\mathrm{a}}$ & $44(31-66)^{\mathrm{a}}$ \\
\hline Insulin resistance $(\%)^{\mathrm{d}}$ & 8 & 5 & 36 & 47 & 74 & 82 \\
\hline Fasting proinsulin (pmol/l) & $9(5-14)^{\mathrm{a}}$ & $13(7-19)^{\mathrm{a}}$ & $13(8-21)^{\mathrm{a}}$ & $16(9-24)^{\mathrm{a}}$ & $22(12-31)^{\mathrm{a}}$ & $23(9-42)^{\mathrm{a}}$ \\
\hline Body mass index $\left(\mathrm{kg} / \mathrm{m}^{2}\right)$ & $26.0 \pm 3.4$ & $26.9 \pm 3.6$ & $27.9 \pm 4.0$ & $27.1 \pm 3.8$ & $28.2 \pm 4.1$ & $29.7 \pm 5.4$ \\
\hline Waist-to-hip ratio (female) & $0.83 \pm 0.07$ & $0.88 \pm 0.06$ & $0.88 \pm 0.07$ & $0.87 \pm 0.07$ & $0.91 \pm 0.08$ & $0.94 \pm 0.05$ \\
\hline Waist-to-hip ratio (male) & $0.94 \pm 0.06$ & $0.99 \pm 0.06$ & $0.98 \pm 0.06$ & $0.96 \pm 0.06$ & $0.99 \pm 0.08$ & $0.99 \pm 0.06$ \\
\hline Total cholesterol (mmol/l) & $6.7 \pm 1.1$ & $6.1 \pm 1.0$ & $6.8 \pm 1.3$ & $6.7 \pm 1.3$ & $6.4 \pm 1.3$ & $6.6 \pm 1.3$ \\
\hline LDL-cholesterol (mmol/l) & $4.6 \pm 1.0$ & $4.2 \pm 0.9$ & $4.7 \pm 1.1$ & $4.5 \pm 1.1$ & $4.2 \pm 1.1$ & $4.2 \pm 1.1$ \\
\hline HDL-cholesterol (mmol/l) & $1.4 \pm 0.4$ & $1.3 \pm 0.4$ & $1.3 \pm 0.3$ & $1.2 \pm 0.3$ & $1.1 \pm 0.3$ & $1.1 \pm 0.3$ \\
\hline Triglycerides (mmol/l) & $1.4(1.1-1.9)^{\mathrm{a}}$ & $1.2(0.8-1.4)^{\mathrm{a}}$ & $1.6(1.2-2.2)^{\mathrm{a}}$ & $2.4(1.6-2.9)^{\mathrm{a}}$ & $1.9(1.3-2.7)^{\mathrm{a}}$ & $1.5(1.2-4.4)^{\mathrm{a}}$ \\
\hline Diastolic blood pressure $(\mathrm{mmHg})$ & $81 \pm 10$ & $81 \pm 10$ & $83 \pm 9$ & $93 \pm 13$ & $82 \pm 10$ & $84 \pm 13$ \\
\hline Systolic blood pressure $(\mathrm{mmHg})$ & $133 \pm 18$ & $137 \pm 20$ & $141 \pm 17$ & $156 \pm 28$ & $140 \pm 18$ & $153 \pm 19$ \\
\hline Hypertension (\%) $)^{\mathrm{e}}$ & 21 & 40 & 42 & 73 & 46 & 79 \\
\hline Current smokers (\%) & 30 & 25 & 22 & 13 & 24 & 24 \\
\hline Ex-smokers (\%) & 34 & 50 & 36 & 53 & 34 & 39 \\
\hline
\end{tabular}

Data are mean \pm standard deviation unless otherwise indicated. ${ }^{\mathrm{a}}$ median $\left(25-75\right.$ th percentiles); ${ }^{\mathrm{b}}$ percentage of subjects with fasting insulin levels in the highest tertile in the whole sample $(>101 \mathrm{pmol} / \mathrm{l}) ;{ }^{\mathrm{c}} \mathrm{HOMA}=$ fasting insulin $\times$ fasting glucose/22.4; ${ }^{\mathrm{d}}$ percentages of subjects with IR in the highest ter- tile in the whole sample $\left(>29.8 \mathrm{pmol} \cdot \mathrm{mmol} \cdot \mathrm{l}^{-2}\right)$; ${ }^{\mathrm{e}}$ Hypertension is defined as diastolic blood pressure $>95 \mathrm{mmHg}$ and/ or systolic blood pressure $>160 \mathrm{mmHg}$ and/or the use of antihypertensive drugs 
Table 2. Age-, sex- and glucose tolerance-adjusted odds ratios (95\% confidence intervals) for microalbuminuria of insulin resistance syndrome-related variables

\begin{tabular}{llll}
\hline & All subjects $(n=622)$ & Non-diabetic subjects $(n=467)$ & Diabetic subjects $(n=155)$ \\
\hline Hypertension $_{\text {NIDDM }^{\mathrm{a}}}$ & $3.29(1.86-5.82)$ & $2.72(1.31-5.67)$ & $3.99(1.56-10.22)$ \\
Impaired glucose tolerance $^{\mathrm{b}}$ & $3.35(1.83-6.12)$ & & \\
Dyslipidaemia $^{\mathrm{c}}$ & $1.21(0.60-2.45)$ & $1.24(0.61-2.51)$ & $1.07(0.47-2.44)$ \\
Waist-to-hip ratio $^{\mathrm{d}, \mathrm{e}}$ & $1.14(0.66-1.96)$ & $1.06(0.50-2.23)$ & $3.67(0.45-30.15)$ \\
Fasting hyperinsulinaemia $^{\mathrm{f}}$ & $2.41(1.10-5.29)$ & $2.49(1.02-6.05)$ & $0.93(0.30-2.89)$ \\
Insulin resistance $^{\mathrm{g}}$ & $1.39(0.68-2.84)$ & $1.56(0.61-4.00)$ & $1.96(0.23-16.86)$ \\
Fasting hyperproinsulinaemia $^{\mathrm{h}, \mathrm{i}}$ & $1.84(0.78-4.36)$ & $1.45(0.51-4.15)$ & $0.30(0.04-2.06)$ \\
\hline
\end{tabular}

${ }^{\mathrm{a}}$ compared to subjects with normal glucose tolerance; ${ }^{\mathrm{b}}$ compared to subjects with normal glucose tolerance; ${ }^{\mathrm{c}}$ defined as HDL-cholesterol in the lowest and/or triglycerides levels in the highest tertile; ${ }^{\mathrm{d}}$ the highest compared to the lowest tertile of waist-to-hip ratio per sex; ${ }^{\mathrm{e}}$ associations with BMI were weaker; ${ }^{\mathrm{f}}$ highest (>101 pmol/1) compared to the lowest tertile

betic and non-diabetic subjects, $16.4 \%$ and $5.9 \%$ among hypertensive and non-hypertensive subjects, and $5.4 \%$ among normotensive non-diabetic subjects).

Among NGT subjects, those with MA were older and had higher WHR and systolic blood pressure than did those with normoalbuminuria. Among diabetic subjects, $\mathrm{HbA}_{1 \mathrm{c}}$ and systolic blood pressure were higher in the micro- than in the normoalbuminuric subjects. Thirty-eight percent of the diabetic subjects were previously known diabetic subjects. The IR and fasting insulin levels were similar between newly detected and previously known diabetic subjects (data not shown). Among NGT, IGT and NIDDM subjects, the prevalence of hypertension was higher among those with compared to those without MA (Table 1).

Age-, sex- and glucose tolerance-adjusted analyses showed MA to be significantly associated with hypertension, NIDDM and WHR (Table 2). MA was associated with hypertension and WHR in the non-diabetic subjects and with hypertension among diabetic subjects. Analyses of NGT and IGT subjects separately showed MA to be associated with hypertension and WHR but not with the other IRS-related variables (data not shown). As a consequence of the low prevalence of MA among NGT and IGT subjects (20/295 and 15/172, respectively), these analyses were unstable.

To further investigate the association between MA and IRS-related variables, multiple logistic regression analyses were performed with age, sex, NIDDM, IGT, hypertension, fasting hyperinsulinaemia, dyslipidaemia and WHR as independent variables. MA was significantly associated with NIDDM, hypertension and WHR. Analyses of the non-diabetic and the diabetic subjects separately showed similar results (Table 3), as did multiple regression analyses with IR or hyperproinsulinaemia replacing hyperinsulinaemia (i.e. the second and third model referred to in the of fasting insulin levels; ${ }^{\mathrm{g}}$ according to the HOMA-formula (= fasting insulin $\times$ fasting glucose/22.4), comparing the highest $\left(>29.8 \mathrm{pmol} \cdot \mathrm{mmol} \cdot \mathrm{l}^{-2}\right)$ with the lowest tertile of insulin

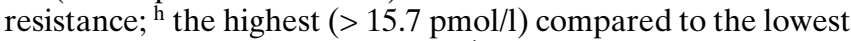
tertile of fasting proinsulin levels; ${ }^{\mathrm{i}}$ obtained in all subjects except for the previously known diabetic subjects

Table 3. Multiple logistic regression analyses with microalbuminuria as dependent variable and insulin resistance syndrome-related variables as independent variables

\begin{tabular}{|c|c|c|}
\hline & OR $(95 \% \mathrm{CI})$ & $p$-value \\
\hline \multicolumn{3}{|l|}{ All subjects $(n=622)$} \\
\hline $\begin{array}{l}\text { Non-insulin-dependent diabetes } \\
\text { mellitus }\end{array}$ & $2.26(1.14-4.48)$ & 0.02 \\
\hline Hypertension & $3.33(1.86-5.96)$ & 0.0001 \\
\hline Fasting hyperinsulinaemia ${ }^{a}$ & $0.97(0.46-2.06)$ & 0.93 \\
\hline Dyslipidaemia $^{\mathrm{b}}$ & $0.79(0.44-1.42)$ & 0.43 \\
\hline Waist-to-hip ratio ${ }^{c}$ & $2.49(1.09-5.70)$ & 0.03 \\
\hline \multicolumn{3}{|l|}{ Non-diabetic subjects $(n=467)$} \\
\hline Impaired glucose tolerance & $0.93(0.43-2.00)$ & 0.86 \\
\hline Hypertension & $2.69(1.25-5.75)$ & 0.01 \\
\hline Fasting hyperinsulinaemia ${ }^{a}$ & $0.96(0.34-2.68)$ & 0.93 \\
\hline Dyslipidaemia $^{\mathrm{b}}$ & $0.77(0.35-1.69)$ & 0.51 \\
\hline Waist-to-hip ratio ${ }^{c}$ & $2.67(1.04-5.75)$ & 0.04 \\
\hline \multicolumn{3}{|l|}{ Diabetic subjects $(n=155)$} \\
\hline Hypertension & $4.31(1.60-11.56)$ & 0.004 \\
\hline Fasting hyperinsulinaemia ${ }^{\mathrm{a}}$ & $0.86(0.26-2.86)$ & 0.81 \\
\hline Dyslipidaemia $^{\mathrm{b}}$ & $0.72(0.29-1.77)$ & 0.74 \\
\hline Waist-to-hip ratio ${ }^{c}$ & $3.78(0.41-34.74)$ & 0.24 \\
\hline
\end{tabular}

Age, sex, non-insulin-dependent diabetes mellitus, impaired glucose tolerance, hypertension, fasting hyperinsulinaemia, dyslipidaemia and waist-to-hip ratio were independent variables adjusted for each other; ${ }^{\mathrm{a}}$ the highest compared to the lowest tertile of fasting insulin levels, ${ }^{\mathrm{b}}$ defined as HDL-cholesterol in the lowest and/or triglycerides in the highest tertile, ${ }^{\mathrm{c}}$ the highest compared to the lowest tertile of waist-to-hip ratio per sex; $\mathrm{OR}=$ odds ratio; $95 \% \mathrm{CI}=95 \%$ confidence interval

Data analysis section; data not shown). We also investigated whether the association between MA and WHR was confounded by protein intake by performing analyses with daily protein intake (total, animal or vegetable; $\mathrm{g} / \mathrm{kg} / \mathrm{day}$ ) in the regression model; there was no confounding (data not shown).

The above analyses suggested that hypertension and NIDDM were major determinants of MA, while other IRS-related variables were not. To investigate this issue further, we created two Z-scores (see Subjects and methods). The prevalence of MA increased 


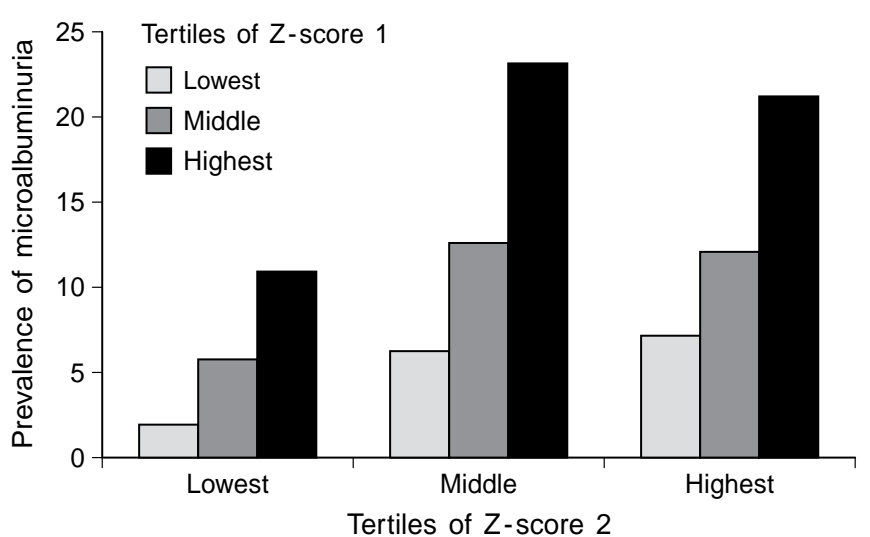

Fig. 2. Prevalence of microalbuminuria for different $Z$-scores. $\mathrm{Z}$-score 1 is the sum of the Z-scores of systolic and diastolic blood pressure and fasting glucose levels, and Z-score 2 is the sum of the Z-scores of waist-to-hip ratio, fasting insulin, HDL-cholesterol and triglycerides levels

when the Z-score of glucose level and systolic and diastolic blood pressure increased, but not when the Zscore of the remaining IRS-related variables increased (Fig. 2). Sex- and age-adjusted regression analyses with these two Z-scores as independent variables showed a significant association with MA for the Z-score of blood pressure and fasting glucose (OR 1.89[1.32-2.70]), but not for the Z-score of the other IRS-related variables $(\mathrm{OR}=1.39[0.98-2.00])$. These results were similar for non-diabetic and diabetic subjects separately (data not shown).

We repeated the multiple regression analyses for the 174 subjects who had handed in two urine samples, for one sample only and for the mean of two samples. The results were similar, i. e. only hypertension and NIDDM were statistically significantly associated with MA (data not shown). We also investigated whether the definition of MA affected the results. However, the results of the multiple regression analyses were similar, whether MA was defined as an ACR over $2.5 \mathrm{mg} / \mathrm{mmol}$ for men and an ACR over $3.5 \mathrm{mg} /$ mmol for women ([37]; prevalence, $7.7 \%$ [48/622]), as an ACR $1.5 \mathrm{mg} / \mathrm{mmol}$ for both sexes ([4]; prevalence, $15.1 \%$ [94/622]), or as ACR over $2.0 \mathrm{mg} /$ mmol while excluding subjects with leukocyturia ( $n=136$; data not shown).

\section{Discussion}

This study shows that, in an ethnically homogeneous, Caucasian population aged 50-75 years, MA is strongly associated with hypertension, NIDDM and WHR, but not with other components of the IRS, i. e. insulin resistance, hyperinsulinaemia and dyslipidaemia. This suggests that MA is more likely to be a complication of NIDDM and (or) hypertension than a part of the IRS.
MA is thought to be a consequence of an increased leakage of albumin through the glomerular basement membrane as a result of increased intraglomerular capillary pressure, increased permeability of the glomerular capillary wall, or both [38]. Both hypertension and NIDDM can increase intraglomerular pressure [39]; hyperglycaemia, moreover, can induce loss of negative charges on the glomerular basement membrane and thus increase permeability to negatively charged proteins such as albumin [40]. Thus, there is a clear pathophysiological basis for the association of MA with NIDDM and hypertension, which strongly suggests that MA can arise as a complication of these phenomena. In contrast, there is no conclusive evidence that insulin resistance, hyperinsulinaemia or dyslipidaemia increase intraglomerular pressure and / or impair glomerular charge selectivity and thus lead directly to MA [41, 42]. Taken together, these findings argue against MA being an integral part of the IRS.

We did find that WHR, as a marker of central obesity, was associated with the presence of MA independently of NIDDM and hypertension. Recently, it has been reported that an increased urinary albumin excretion is associated with a higher body mass index [13]. One might argue that the association of central obesity with MA is consistent with the concept that MA is a part of the IRS. If this were the case, however, it is difficult to explain why MA turned out not to be associated with the other components of the IRS. In addition, several other mechanisms unrelated to the IRS may account for the association between central obesity and MA. Firstly, obese subjects may have a higher protein intake, which may increase the intraglomerular pressure [43]. In the present study, however, protein intake did not explain the association between WHR and MA. Secondly, recent data indicate that central adipose tissue may be a source of cytokines such as tumour necrosis factor- $\alpha$ [44], which can increase glomerular permeability [45]. Finally, through mechanisms that have not been elucidated, the overweight condition may be associated with renal haemodynamic changes, such as hyperperfusion and hyperfiltration, that tend to increase intraglomerular pressure [46].

Previous cross-sectional $[6,8,11,14]$ and prospective [9] studies have shown that IR, as determined with the euglycaemic hyperinsulinaemic clamp technique, was more severe in the presence of MA than in its absence. However, these studies were performed in highly selected subjects and cannot establish whether MA is intrinsically linked to IR and the IRS in the general population. Epidemiological studies of the associations of MA with IRS-related variables have not yielded consistent results $[7,10,16,18$, 21-23]. In our study we found no association between MA and the IRS, even in Z-score analyses in which weak associations might reveal themselves by being 
considered in combination. It is noteworthy that some studies that reported a positive association between MA and the IRS did not adjust for (central) obesity $[6,8,14,16]$, which would be desirable if (central) obesity was linked to MA through mechanisms independent of the IRS. In addition, the association between MA and the IRS may be different among different ethnic groups. It is remarkable that MA appears to be more closely related to hyperinsulinaemia and dyslipidaemia in non-diabetic populations with a low $[10,16]$ than in those with a high prevalence of hypertension [18, 21]. Thus, if a link between MA and the IRS does exist among non-diabetic subjects, it seems to be most prominent among populations with a low prevalence of hypertension.

Can methodological issues explain our results? Firstly, we collected only one urine sample from most subjects. As microalbuminuria is quite variable from day-to-day, this may have decreased the overall statistical power of the study. However, day-to-day variability is probably lessened somewhat by collecting overnight urine [47], as we did, and by expressing albumin excretion as an albumin-to-creatinine ratio [48]. In addition, analyses for the 176 subjects from whom two urine samples were collected yielded essentially similar results. Secondly, we chose an ACR over $2.0 \mathrm{mg} /$ $\mathrm{mmol}$ as the cut-off for MA. If the association between MA and the IRS would depend on a certain threshold for MA, we may have missed any such association by our choice of the threshold. However, analyses with a higher or a lower threshold gave similar results.

In conclusion, in an ethnically homogeneous, Caucasian population aged 50-75 years, the presence of microalbuminuria was associated with the presence of NIDDM and hypertension and with waist-to-hip circumference ratio, but not with other components of the IRS. We suggest that MA is not a useful marker of the IRS in Caucasian populations. This contrasts with data obtained in other ethnic groups [16]. Taken together, these findings suggest that the relationship between the IRS and MA may be modified by ethnicity or related factors, such as the prevalence of hypertension.

\section{References}

1. Mogensen CE (1984) Microalbuminuria predicts clinical proteinuria and early mortality in maturity-onset diabetes. N Engl J Med 310: 356-360

2. Schmitz A, Vaeth M (1988) Microalbuminuria: a major risk factor in non-insulin-dependent diabetes. A 10-year followup study of 503 patients. Diabet Med 5: 126-134

3. Mattock MB, Morrish NJ, Viberti G, Keen H, Fitzgerald AP, Jackson G (1992) Prospective study of microalbuminuria as predictor of mortality in NIDDM. Diabetes 41: 736-741

4. Damsgaard EM, Froland A, Jorgensen OD, Mogensen CE (1990) Microalbuminuria as predictor of increased mortality in elderly people. BMJ 300: 297-300
5. Yudkin JS, Forrest RD, Jackson CA (1988) Microalbuminuria as predictor of vascular disease in non-diabetic subjects. Islington Diabetes Survey. Lancet II: 530-533

6. Groop L, Ekstrand A, Forsblom C et al. (1993) Insulin resistance, hypertension and microalbuminuria in patients with type 2 (non-insulin-dependent) diabetes mellitus. Diabetologia 36: 642-647

7. Chan JC, Tomlinson B, Nicholls MG et al. (1996) Albuminuria, insulin resistance and dyslipidaemia in Chinese patients with non-insulin-dependent diabetes (NIDDM). Diabet Med 13: 150-155

8. Nosadini R, Cipollina MR, Solini A et al. (1992) Close relationship between microalbuminuria and insulin resistance in essential hypertension and non-insulin dependent diabetes mellitus. J Am Soc Nephrol [ Suppl]:S56-S63

9. Nosadini R, Solini A, Velussi M et al. (1994) Impaired insulin-induced glucose uptake by extrahepatic tissue is a hallmark of NIDDM patients who have or will develop hypertension and microalbuminuria. Diabetes 43: 491-499

10. Haffner SM, Gonzales C, Valdez RA et al. (1993) Is microalbuminuria part of the prediabetic state? The Mexico City Diabetes Study. Diabetologia 36: 1002-1006

11. Forsblom CM, Eriksson JG, Ekstrand AV, Teppo AM, Taskinen MR, Groop LC (1995) Insulin resistance and abnormal albumin excretion in non-diabetic first-degree relatives of patients with NIDDM. Diabetologia 38: 363-369

12. Agewall S, Fagerberg B, Attvall S et al. (1995) Microalbuminuria, insulin sensitivity and haemostatic factors in nondiabetic treated hypertensive men. Risk Factor Intervention Study Group. J Intern Med 237: 195-203

13. Metcalf P, Baker J, Scott A, Wild C, Scragg R, Dryson E (1992) Albuminuria in people at least 40 years old: effect of obesity, hypertension, and hyperlipidemia. Clin Chem 38: 1802-1808

14. Niskanen L, Laakso M (1993) Insulin resistance is related to albuminuria in patients with type II (non-insulin-dependent) diabetes mellitus. Metabolism 42: 1541-1545

15. Mykkanen L, Haffner SM, Kuusisto J, Pyorala K, Laakso M (1994) Microalbuminuria precedes the development of NIDDM. Diabetes 43: 552-557

16. Haffner SM, Stern MP, Gruber MK, Hazuda HP, Mitchell BD, Patterson JK (1990) Microalbuminuria. Potential marker for increased cardiovascular risk factors in non-diabetic subjects? Arteriosclerosis 10: 727-731

17. Niskanen L, Uusitupa M, Sarlund H et al. (1990) Microalbuminuria predicts the development of serum lipoprotein abnormalities favouring atherogenesis in newly diagnosed type 2 (non-insulin-dependent) diabetic patients. Diabetologia 33: 237-243

18. Winocour PH, Harland JO, Millar JP, Laker MF, Alberti KG (1992) Microalbuminuria and associated cardiovascular risk factors in the community. Atherosclerosis 93: $71-81$

19. Stehouwer CDA, Nauta JJ, Zeldenrust GC, Hackeng WHL, Donker AJM, den Ottolander GJH (1992) Urinary albumin excretion, cardiovascular disease, and endothelial dysfunction in non-insulin-dependent diabetes mellitus. Lancet 340: 319-323

20. Pedrinelli R, Giampietro O, Carmassi F et al. (1994) Microalbuminuria and endothelial dysfunction in essential hypertension. Lancet 344: 14-18

21. Foyle WJ, Carstensen E, Fernandez MC, Yudkin JS (1995) Longitudinal study of associations of microalbuminuria with the insulin resistance syndrome and sodium-lithium countertransport in nondiabetic subjects. Arterioscler Thromb Vasc Biol 15: 1330-1337 
22. Nielsen S, Schmitz O, Orskov H, Mogensen CE (1995) Similar insulin sensitivity in NIDDM patients with normoand microalbuminuria. Diabetes Care 18: 834-842

23. Haffner SM, Morales PA, Gruber MK, Hazuda HP, Stern MP (1993) Cardiovascular risk factors in non-insulin-dependent diabetic subjects with microalbuminuria. Arterioscler Thromb 13: 205-210

24. Metcalf PA, Baker JR, Scragg RK, Dryson E, Scott AJ, Wild CJ (1993) Microalbuminuria in a middle-aged workforce. Effect of hyperglycemia and ethnicity. Diabetes Care 16: 1485-1493

25. Alzaid AA, Sobki S, De Silva V (1994) Prevalence of microalbuminuria in Saudi Arabians with non-insulin-dependent diabetes mellitus: a clinic-based study. Diabetes Res Clin Pract 26: 115-120

26. Beks PJ, Mackaay AJ, de Neeling JN, de Vries H, Bouter LM, Heine RJ (1995) Peripheral arterial disease in relation to glycaemic level in an elderly Caucasian population: the Hoorn Study. Diabetologia 38: 86-96

27. World Health Organization Study Group on Diabetes Mellitus (1985) Technical Report Series No 727, WHO, Geneva

28. Mooy JM, Grootenhuis PA, de Vries H, Kostense PJ, Popp-Snijders C, Bouter LM, Heine RJ (1996) Intra-individual variation of glucose, specific insulin and proinsulin concentrations measured by two oral glucose tolerance tests in a general Caucasian population: the Hoorn Study. Diabetologia 39: 298-305

29. Friedewald WT, Levy RI, Fredrickson DS (1972) Estimation of the concentration of low-density lipoprotein cholesterol in plasma, without use of the preparative ultracentrifuge. Clin Chem 18: 499-502

30. Gatling W, Knight C, Mullee MA, Hill RD (1988) Microalbuminuria in diabetes: a population study of the prevalence and an assessment of three screening tests. Diabet Med 5: 343-347

31. Landis JR, Koch GG (1977) The measurement of observer agreement for categorical data. Biometrics 33: 159-174

32. DeFronzo RA, Ferrannini E (1991) Insulin resistance. A multifaceted syndrome responsible for NIDDM, obesity, hypertension, dyslipidemia, and atherosclerotic cardiovascular disease. Diabetes Care 14: 173-194

33. Reaven GM (1988) Banting lecture 1988. Role of insulin resistance in human disease. Diabetes 37: 1595-1607

34. Matthews DR, Hosker JP, Rudenski AS, Naylor BA, Treacher DF, Turner RC (1985) Homeostasis model assessment: insulin resistance and beta-cell function from fasting plasma glucose and insulin concentrations in man. Diabetologia 28: 412-419
35. Laakso M (1993) How good a marker is insulin level for insulin resistance? Am J Epidemiol 137: 959-965

36. Phillips DI, Clark PM, Hales CN, Osmond C (1994) Understanding oral glucose tolerance: comparison of glucose or insulin measurements during the oral glucose tolerance test with specific measurements of insulin resistance and insulin secretion. Diabet Med 11: 286-292

37. Mogensen CE, Keane WF, Bennett PH et al. (1995) Prevention of diabetic renal disease with special reference to microalbuminuria. Lancet 346: 1080-1084

38. Brenner BM, Hostetter TH, Humes HD (1978) Molecular basis of proteinuria of glomerular origin. $\mathrm{N}$ Engl J Med 298: 826-833

39. Ljungman S (1990) Microalbuminuria in essential hypertension. Am J Hypertens 3: 956-960

40. Shimomura H, Spiro RG (1987) Studies on macromolecular components of human glomerular basement membrane and alterations in diabetes. Decreased levels of heparan sulfate proteoglycan and laminin. Diabetes 36: 374-381

41. Juncos LA, Ito S (1993) Disparate effects of insulin on isolated rabbit afferent and efferent arterioles. J Clin Invest 92: 1981-1985

42. Fujihara CK, Padilha RM, Zatz R (1992) Glomerular abnormalities in long-term experimental diabetes. Role of hemodynamic and nonhemodynamic factors and effects of antihypertensive therapy. Diabetes 41: 286-293

43. Brenner BM, Meyer TW, Hostetter TH (1982) Dietary protein intake and the progressive nature of kidney disease: the role of hemodynamically mediated glomerular injury in the pathogenesis of progressive glomerular sclerosis in aging, renal ablation, and intrinsic renal disease. $\mathrm{N}$ Engl $\mathbf{J}$ Med 307: 652-659

44. Hotamisligil GS, Arner P, Caro JF, Atkinson RL, Spiegelman BM (1995) Increased adipose tissue expression of tumor necrosis factor-alpha in human obesity and insulin resistance. J Clin Invest 95: 2409-2415

45. Baud L, Ardaillou R (1994) Tumor necrosis factor alpha in glomerular injury. Kidney Int [Suppl] S32-S36

46. Ribstein J, du Cailar G, Mimran A (1995) Combined renal effects of overweight and hypertension. Hypertension 26: 610-615

47. Hutchison AS, Paterson KR (1988) Collecting urine for microalbumin assay. Diabet Med 5: 527-532

48. Price DA, Davies AG (1985) Short-term variability of urinary albumin excretion in normal and diabetic children. Diabetic Nephropathy 4: 169-171 